\title{
Sensory Input Pathways and Mechanisms in Swallowing: A Review
}

\author{
Catriona M. Steele $\cdot$ Arthur J. Miller
}

Received: 8 December 2009/Accepted: 14 August 2010/Published online: 3 September 2010

(C) The Author(s) 2010. This article is published with open access at Springerlink.com

\begin{abstract}
Over the past 20 years, research on the physiology of swallowing has confirmed that the oropharyngeal swallowing process can be modulated, both volitionally and in response to different sensory stimuli. In this review we identify what is known regarding the sensory pathways and mechanisms that are now thought to influence swallowing motor control and evoke its response. By synthesizing the current state of research evidence and knowledge, we identify continuing gaps in our knowledge of these mechanisms and pose questions for future research.
\end{abstract}

\section{M. Steele $(\bowtie)$}

Toronto Rehabilitation Institute, 550 University Avenue, \#12030, Toronto, ON M5G 2A2, Canada

e-mail: steele.catriona@torontorehab.on.ca

C. M. Steele

Holland Bloorview Kids Rehab, Toronto, ON, Canada

\section{M. Steele}

Department of Speech-Language Pathology,

University of Toronto, Toronto, ON, Canada

\section{M. Steele}

Graduate Department of Rehabilitation Sciences,

University of Toronto, Toronto, ON, Canada

C. M. Steele

Institute of Biomaterials and Biomedical Engineering,

University of Toronto, Toronto, ON, Canada

\section{A. J. Miller}

Division of Orthodontics, Department of Orofacial Sciences,

School of Dentistry, University of California at San Francisco,

San Francisco, CA 94143, USA
Keywords Deglutition - Deglutition disorders · Sensation - Sensory pathways · Physiology

In her recent review on neuroplasticity in swallowing, Martin [1] argues for the potential importance of sensory stimulation as a mechanism for influencing swallowing behavior. Sensory input is vital to the oral, pharyngeal, and esophageal phases of swallowing, yet evaluation of the integrity of the afferent pathways carrying sensory information to the swallowing control centers in the brain is not part of the standard clinical or instrumental swallowing assessment [2]. Sensory input informs neural control centers about the process of mastication so that boluses are prepared to a desirable consistency and lingual propulsive forces are tailored to transport the bolus efficiently into the pharynx [3,4]. Sensory input triggers the subconscious pharyngeal swallow and modulates the sequential motor activity of muscles that transport the bolus through the pharynx [5, 6]. Sensory input modifies esophageal swallow intensity and triggers secondary peristalsis [7]. Sensory input synaptically influences multiple pathways, both cortical and brainstem, to trigger swallowing, alter motor output, and simultaneously activate ascending pathways, which reflexively modulate the motor output throughout the swallowing sequence [8].

The pharyngeal phase of swallowing is a well-recognized, complex reflex response [6]. Most experts, however, believe that the pharyngeal swallow involves modulation from sensory input and descending cortical pathways [9-17]. Fundamental studies in animal models indicate that the pharyngeal swallow sequence has a baseline or default mode, a brainstem-driven basic reflex that can then be modified in the normal conscious subject [18]. For example, aspects of the muscular contractile sequence can be modified, including the durations of individual muscle activation and the 
magnitude of EMG activity, reflecting muscle contraction amplitudes [19]. Sensory input is a key mechanism in facilitating such swallow modulation. The goal of this review article is to summarize the existing state of knowledge and research evidence regarding sensory input pathways, mechanisms, and modulation in swallowing (Table 1).

\section{Anatomy Supporting Sensory Input to Swallowing}

\section{Sensory Fibers}

The pharyngeal phase of swallowing is triggered by specific sensory inputs and is then completed by an entire

Table 1 Potential sensory stimuli that modulate or can evoke swallowing

\begin{tabular}{|c|c|c|}
\hline Stimulus & Sensory nerve & Source \\
\hline Gastrointestinal & Olfactory-black pepper oil & Ebihara et al. [35] \\
\hline Cephalic phase & & Maeda et al. [36] \\
\hline \multicolumn{3}{|l|}{ Oral phase } \\
\hline & Maxillary division (V2) & Pouderoux and Kahrilas [39] and Sweazey and Bradley [60] \\
\hline & Mandibular division (V3) & Sweazey and Bradley $[22,23]$ and Thexton $[24]$ \\
\hline Oral splint & & Ali et al. [100] \\
\hline \multicolumn{3}{|l|}{ Pharyngeal phase } \\
\hline \multicolumn{3}{|l|}{ Animal studies } \\
\hline $\begin{array}{l}\text { Electrically stimulate with optimum } \\
\text { frequencies }(30-50 \mathrm{~Hz})\end{array}$ & $\begin{array}{l}\text { Internal branch of the superior } \\
\text { laryngeal nerve (iSLN) }\end{array}$ & Doty [5] \\
\hline $\begin{array}{l}\text { Electrically stimulate with optimum } \\
\text { frequencies }(30-50 \mathrm{~Hz})\end{array}$ & $\begin{array}{l}\text { Pharyngeal branch of the } \\
\text { glossopharyngeal nerve (IXth) }\end{array}$ & Sinclair [82] and Kitagawa et al. [20] \\
\hline Water, tactile, pressure & iSLN & Storey $[84,85]$ \\
\hline Ionic fluids (i.e., $\mathrm{KCl}$ ) & & Shingai $[25,26]$ \\
\hline \multicolumn{3}{|l|}{ Solutions with taste } \\
\hline Sour (citric acid, acetic acid) & & Kajii et al. [124] \\
\hline Thermal stimuli to anterior pillars & & Chi-Fishman et al. [115] \\
\hline \multicolumn{3}{|l|}{ Human studies } \\
\hline Light pressure & & $\begin{array}{l}\text { Kaatzke-McDonald et al. [116], Pommerenke [21], } \\
\text { Rosenbek et al. [118] and Sciortino et al. [121] }\end{array}$ \\
\hline Heavy pressure & & Pommerenke [21] \\
\hline Water & & Shaker et al. $[122,123]$ \\
\hline Sour solutions & & $\begin{array}{l}\text { Logemann et al. [125], Pelletier and Lawless [127], } \\
\text { Hamdy et al. [126] and Sciortino et al. [121] }\end{array}$ \\
\hline Carbonation & & Bulow et al. [150] \\
\hline Thermal stimuli & & $\begin{array}{l}\text { Kaatzke-McDonald et al. [116], Rosenbek et al. [117-119], } \\
\text { Sciortino et al. [121] and Ali et al. [100] }\end{array}$ \\
\hline Suggested nociceptive stimuli & & Pelletier and Lawless [127] and Pelletier and Dhanaraj [128] \\
\hline Airpuffs & & Aviv et al. [107, 108] \\
\hline Volume of bolus & & $\begin{array}{l}\text { Dantas et al. [101], Kahrilas and Logemann [99] } \\
\text { and Lazarus et al. [98] }\end{array}$ \\
\hline Viscosity & & $\begin{array}{l}\text { Christensen and Casper [103], Dantas and Dodds [104] } \\
\text { and Lazarus et al. [98] }\end{array}$ \\
\hline \multirow[t]{2}{*}{ Increased salivation } & IXth & Mansson and Sandberg [32] \\
\hline & iSLN & Mansson and Sandberg [33] \\
\hline $\begin{array}{l}\text { Electrical stimulation to induce } \\
\text { laryngeal closure }\end{array}$ & iSLN & Barkmeier et al. [87] \\
\hline $\begin{array}{l}\text { Site of bolus in pharynx to elicit the } \\
\text { swallow }\end{array}$ & & $\begin{array}{l}\text { Martin-Harris et al. [75], Daniels and Foundas [73], } \\
\text { Daniels et al. [74] and Pouderoux et al. [77] }\end{array}$ \\
\hline \multicolumn{3}{|l|}{ Inhibit or suppress pharyngeal swallowing } \\
\hline $\begin{array}{l}\text { Local anesthesia to the paraglottic } \\
\text { compartment of the pharynx }\end{array}$ & iSLN & Jafari et al. [86] \\
\hline $\begin{array}{l}\text { Local anesthesia to the laryngeal } \\
\text { mucosa }\end{array}$ & iSLN & Sulica et al. [88] \\
\hline
\end{tabular}


sequence of bilateral muscle activity [6]. Doty [5] was the first to define the pharyngeal swallow as the most complex reflex elicited by the central nervous system (CNS) and demonstrate that sensory input is integral to "triggering" the response. Afferent input related to swallowing travels via sensory fibers in the trigeminal nerve (Vth), the glossopharyngeal nerve (IXth), the internal branch of the superior laryngeal nerve (iSLN), and other branches of the vagus nerve [20]. Doty's original studies (and multiple subsequent studies) in the experimental animal have accentuated the importance of the iSLN [5]. Studies in the human using probes with light and heavy pressure have implicated receptors in certain oropharyngeal regions as contributing more than others to evoking the pharyngeal swallow [21]. Deep pressure tactile receptors stimulate sensory fibers that directly synapse in the brainstem [22-24]. Animal studies have shown that receptive fields around the faucial pillars and throughout the pharynx can be stimulated with specific sensory stimuli that include water and a variety of ionic fluids [25, 26]. The esophagus also depends on continued sensory input [27]. Direct infusion of a bolus into the esophagus induces peristaltic contractions that proceed from striated to smooth muscle in an uninterrupted progression [28-31]. Such sensory input uses both brainstem and local neural loops through ganglia in the esophagus [31].

\section{Pathways that Enable Sensory Input to Influence} Swallowing

Afferent input that may affect the threshold to induce swallowing can include stimuli that increase salivation $[32,33]$. Introduction of food or liquid to the visual and auditory senses, as well as to the mouth, initiates the cephalic phase of control of the gastrointestinal tract, establishing the neurophysiological context in which swallowing emerges $[34,35]$. Concepts of providing visual cues related to drinking [36] or strong olfactory stimuli to induce increased salivation to facilitate swallowing are valuable new approaches.

During the oral phase of swallowing, afferent input is carried predominantly by trigeminal sensory fibers from the maxillary and mandibular divisions (V2, V3), which send input into the trigeminal sensory nuclei [23, 37]. Sensory information about touch and pressure transmits over fibers that synapse in the principal sensory nucleus of the trigeminal system. The tongue and palate have touch and pressure receptors that provide distributed sensory input over multiple fibers so that complex input (e.g., information about bolus texture, shape, and size) can be read within the CNS [38]. Studies in the lamb show that tactile receptive fields on the tongue often have reciprocal receptive fields on the hard palate so that sensory input to both structures can be generated by a bolus between the two tissues [23, 37]. The CNS uses sensory information from the oral cavity to inform and guide both tongue shape and the associated pressures that are generated to squeeze the bolus successfully toward the pharynx [39]. Placing a splint in the mouth of normal subjects to alter tongue movements and position significantly reduces the peak midpharyngeal pressure and hypopharyngeal intrabolus pressure [40]. The splint in the mouth also delays the onset of hyoid motion and relaxation of the upper esophageal sphincter (UES).

Taste, the other form of afferent input arising in the mouth, travels via the chorda tympani branch of the facial nerve (VII) and synapses predominantly in the nucleus tractus solitarius (NTS) [41, 42]. Studies by Hamdy et al. [15] indicate that regardless of the type of sensory taste stimulation (sweet, sour, salty, or bitter), the same four to five regions of the cortex are excited, including the insula and primary sensory cortex (regions that are known to be active during swallowing). Chemical stimulation of the amygdala and nucleus accumbens with dopamine and apomorphine facilitates pharyngeal swallowing induced by electrical stimulation of the SLN in an anesthetized cat [43].

The pharyngeal epithelium is richly innervated with sensory fibers, but deep receptors are less common than in the oral cavity [44]. The greatest density of pharyngeal sensory receptors is found at the junction of the naso- and oropharynx [45-47]. The laryngeal and epiglottic epithelia contain both superficial and deep nerve terminals, predominantly in the form of free nerve endings [48]. The highest density of laryngeal sensory receptors is located in the supraglottic mucosa near the arytenoid cartilages [49]. The laryngeal surface of the epiglottis has many more sensory fibers than the lingual surface [48]. The cell bodies for these sensory fibers reside in the sensory ganglia of the trigeminal, glossopharyngeal, and vagal nerves [50]. The glossopharyngeal nerve (IXth) and the pharyngeal branch of the vagus nerve (Xth) primarily innervate the pharynx, and their afferent fibers are interwoven in a dense plexus [44].

\section{Central Connections}

Sensory fibers of the glossopharyngeal and vagus nerves synapse directly in the NTS and do not appear to synapse in the trigeminal sensory nuclei [20]. Transynaptic neural tracers like the pseudorabies virus (PRV), when injected to affect vagal afferents in the rat, show that the sensory fibers terminate in the interstitial and intermediate NTS subnuclei [51]. Another anterograde and retrograde tracer, cholera toxin horseradish peroxidase (CT-HRP), shows that palatal, pharyngeal, and laryngeal afferents overlap in their synaptic contacts in the interstitial and intermediate NTS subnuclei, while esophageal afferents terminate exclusively 
in the central subnucleus [52]. These sensory neurons contain both excitatory and inhibitory neurotransmitters, including glutamate and $\gamma$-aminobutyric acid (GABA).

To date, much of the research regarding afferent influences in swallowing has been derived from animal models or studies of healthy human subjects. Jean et al. [53, 54] has shown the importance of the NTS as the "dorsal swallowing group" (DSG) in the brainstem swallowing control centers or "central pattern generator." Sensory input must proceed and synapse in the DSG region. Such sensory input may partially include trigeminal sensory input, but it always involves input from the pharyngeal branch of the glossopharyngeal nerve (GPNph) and the iSLN. Work by Sumi [55-57] and Amri et al. $[58,59]$ has provided electrophysiological evidence that sensory fibers from the iSLN bifurcate to synapse in and around the NTS, and, simultaneously, to proceed rostrally. This ascending sensory input lays the anatomical foundation that facilitates cortical interaction in the process of pharyngeal swallow initiation. The ascending pathways transmit sensory information to higher regions in the brainstem, subcortical, and cortical levels.

Sweazey and Bradley's studies [22, 23, 60] in sheep have provided much of the experimental information about sensory input from the oropharynx. The majority of neurons in the lamb trigeminal nucleus respond to mechanical stimulation, while a few respond to thermal input and very few to chemical stimuli. Convergence of receptive fields does not occur often. By contrast, neurons in the NTS are more responsive to chemical and mechanical stimuli, and many have multimodal responses $[22,61,62]$. The finding that the NTS neurons are more multimodal supports the concept that reflex initiation of pharyngeal swallowing would involve neurons that respond to multiple types of stimuli.

Detailed studies of taste reception show that the trigeminal and glossopharyngeal nerve (GPN) fibers that carry this information synapse in the rostral NTS [63, 64]. Whether some of these afferent fibers also synapse at the more middle and caudal regions of the NTS (i.e., in the "dorsal swallowing region") remains unproven [63, 65]. The synaptic connections between taste sensory input pathways and the primary swallowing pathways needs further analysis.

Sensory input from both the pharynx and the esophagus is vital to the esophageal phase of swallowing. Esophageal sensory input proceeds both locally using enteric reflexes and rostrally to the brainstem [7]. Detailed experimental studies of vagal afferents innervating the esophagus indicate that short-activity neurons respond during swallowing but not to activity of the longitudinal muscles, while longactivity neurons respond to distension as mechanoreceptor neurons [27, 66-68]. Recordings from primary afferent fibers of the vagus nerve, the thoracic sympathetic nerves, and the splanchnic nerves of the opossum showed different patterns of sensitivity to esophageal distension [68]. Some vagal afferent fibers were low-threshold mechanoreceptors, responding to pressures as low as $0.29 \mathrm{mmHg}$ and increasing their discharge to pressures of $50-70 \mathrm{mmHg}$. Distension-sensitive afferents in the thoracic sympathetic and splanchnic nerves were either wide-dynamic-range or high-threshold mechano-pain receptors.

\section{Potential Mechanisms to Alter Swallowing}

Observed Variations Demonstrate the Potential for Sensory Modulation

Evidence of the potential for sensory modulation of swallowing can be drawn from variations observed in swallow physiology across different bolus consistencies and subjects [69]. Palmer et al. [70, 71] showed that the ingestion of solid foods involves transport of the bolus to the occlusal surface of the molar teeth, chewing by the molar teeth to reduce the bolus to smaller-size pieces, and subsequent further transport of the bolus into the vallecular space, where it collects prior to pharyngeal swallow initiation. This pattern of ingestion contrasts with that usually observed in single (discrete) sips of liquid, in which the bolus is held in a chamber between the dorsal surface of the tongue and the hard palate, and then squeezed in a rostrocaudal direction toward the pharynx by virtue of upward and anteriorly directed tongue movements [39, 72]. Discrete boluses of liquid do not usually accumulate in the hypopharynx prior to swallow onset, except in the case of sequential liquid swallowing and during straw drinking [73, 74].

Martin-Harris and colleagues [75] and Daniels et al. $[73,74]$ have found that healthy subjects vary in their patterns of triggering the pharyngeal swallow. Although discrete boluses of liquid do not usually accumulate in the hypopharynx prior to swallow onset, differences in the pattern of swallow triggering are seen during sequential liquid swallowing and straw drinking. Under these circumstances, some healthy individuals trigger the pharyngeal swallow when the bolus reaches a position on the tongue base parallel to the mandibular ramus; others do not trigger swallowing until the bolus reaches more caudal positions. This pattern varies depending on whether the swallow is the first or a subsequent swallow in a series. Instructing subjects to hold the bolus in their mouth and wait for a command to swallow induces a higher trigger position [76]. Pouderoux et al. [77] have shown that the latency to evoke a pharyngeal swallow is shorter with liquid infusion to deeper positions in the pharynx.

Additional evidence of the potential for sensory modulation in swallowing comes from experiments employing 
(electrical) nerve stimulation and/or sensory inhibition techniques [49, 78-83]. Sinclair [82, 83] showed that swallowing was evoked most effectively by electrical stimulation applied to the pharyngeal branch of the GPN in rabbits. In the rat, swallowing is evoked more easily with mechanical stimulation of the GPN (the posterior pillars, posterior pharyngeal wall, and the soft palate) than with electrical stimulation [20]. Sectioning the pharyngeal branch of GPN eliminates swallow elicitation, while sectioning the lingual branch has no effect [20].

Storey $[84,85]$ showed selective response patterns in cat superior laryngeal nerve fibers to laryngeal cartilage displacement, tactile stimuli $(<0.3 \mathrm{~g})$, pressure $(>0.3 \mathrm{~g})$, water, and saline. Afferent fibers responsive to water overlapped with those responsive to tactile stimuli. Water was specific in inducing maximum discharges from sensory fibers compared to solutions with ions or sugars. Cold stimulation $\left(2^{\circ} \mathrm{C}\right)$ increased tactile fiber activity [84, 85]. Anesthetizing the internal branch of the superior laryngeal nerve (iSLN) by transcutaneous injection of bupivacaine into the paraglottic compartment of healthy humans alters the evoking of swallowing [86]. Under these circumstances, swallowing requires greater effort and is accompanied by an illusory globus sensation in the throat and penetration of fluid into the larynx. Electromyographic recordings from the thyroarytenoid muscle during water swallows show that iSLN stimulation induces laryngeal closure in humans [87]. Intact afferent signals from the iSLN appear necessary to facilitate laryngeal closure in normal deglutition.

Interrupting normal afferent input interferes with healthy swallowing. Endoscopic studies of swallowing, using liquid and puree of different consistencies, have shown that applying anesthesia to the larynx of normal subjects significantly increases spillage, pharyngeal residual material, laryngeal penetration, and tracheal aspiration [88]. Intravenous injection of the inhibitor nitric oxide synthetase (NOS) prolongs latency to fictive swallow induction and the interval between swallows in urethane-anesthetized rats [89].

\section{Effective Mechanisms and Stimuli for Sensory Modulation}

Swallow elicitation appears to involve the activation of multiple sensory fibers across many receptive fields [5]. Sensory physiologists have proposed that normal swallowing stimuli activate "sheets of sensory fibers" so that afferent input proceeds over multiple parallel pathways [90]. When triggering a pharyngeal swallow, some afferent stimuli may contribute to lowering the threshold for swallow initiation in the NTS, the major sensory center in the brainstem swallowing pathway [91, 92]. Direct swallow facilitation can occur when the proper stimuli affect responsive receptive fields with sensory fibers that synapse in the brainstem, exciting the dorsal region around the NTS [54]. Swallow facilitation and modulation can also occur indirectly via ascending cortical pathways that in turn modify the brainstem pathway's threshold to stimuli in the primary receptive zones that evoke pharyngeal swallowing [55, 93]. The importance of sensory input for evoking swallowing is graded, with the most potent stimuli being those detected in the region innervated by the iSLN, immediately above the vocal cords in the hypopharynx $[82,83]$. The sensory stimuli that trigger and modulate swallowing include tactile stimuli (light and heavy pressure, air puffs, different bolus volumes and viscosities), chemical stimuli (water, other solutions, cations, and anions) thermal stimuli, and combined stimulus modalities [84, 85, 94, 95]. Other stimuli may interfere with sensory integrity for swallowing; for example, cigarette smokers have higher thresholds for evoking laryngeal reflexes like vocal cord adduction (i.e., pharyngoglottal closure reflex), UES reflexes (i.e., pharyngo-UES contractile reflex), and pharyngeal swallowing [96, 97].

\section{Tactile Stimuli}

Touch and pressure have been used to stimulate pharyngeal swallowing in human subjects and experimental animals. Larger bolus volumes elicit greater tongue propulsive forces and shorter latencies to evoke the swallow [98-102]. Another bolus characteristic detected via touch and pressure mechanoreception is viscosity [103]. Higher bolus viscosities elicit increases in oropharyngeal transit times [98], intrabolus pressures [104], duration of pharyngeal peristalsis [98], duration of tongue base contact to the posterior pharyngeal wall [98], duration and excursion of hyoid movement [105], and duration of UES relaxation and opening [101, 104].

One of the more recent approaches to evaluate pharyngeal sensory integrity and elicit swallowing has been the use of air puffs [106-108]. Air pulse stimuli have been applied to the mucosa innervated by the iSLN during flexible fiberoptic endoscopic examination of swallowing [109]. When sensation is intact, these air pulses elicit visible tissue reaction at sensory thresholds of less than $4.0 \mathrm{mmHg}$ air pressure, while patients with sensory deficits exhibit higher thresholds [110]. Individuals with normal air pressure sensation do not demonstrate food spillage, laryngeal penetration, or aspiration [111]. Stimulating the arytenoids and interarytenoid areas with air pulses elicits UES contraction (the laryngo-UES contractile reflex) in humans [111]. Studies with air puffs during flexible endoscopy also suggest that the pharyngeal sensation changes with age [107, $108,112]$. The use of air puff stimulation as a mechanism to elicit swallowing is currently under investigation [113, 114]. These studies suggest that healthy individuals 
experience a strong urge to swallow in response to air puffs directed at the posterior faucial arches.

\section{Thermal Stimuli}

Experimental studies have shown that stimulating the anterior pillars with a cold probe while simultaneously stimulating the iSLN increases the number of pharyngeal swallows elicited in the anesthetized adult cat [115]. Ambient $\left(25.3^{\circ} \mathrm{C}\right)$ or cold $\left(8.9^{\circ} \mathrm{C}\right)$ probing of the anterior faucial pillar with a thermode did not induce swallowing in this preparation. Several studies in the human have evaluated temperature stimulation applied to the faucial pillars (e.g., bilateral light stroking with an ice-cold laryngeal mirror) [116-121]. Cold stimulation of the anterior tonsillar pillars in healthy subjects did not affect regional transit and clearance times or UES coordination [102]. Metal probes were found to warm to body temperature during the time between removal from a cup of ice chips and arrival at the faucial pillar; light faucial pillar stimulation with these probes did not change swallow latency or frequency [116]. The latency to swallowing-associated submental muscle activity during evoked swallowing has been shown to be shorter following combined mechanical, cold, and gustatory stimulation, but the effect did not persist beyond the first swallow during continuous infusion of water following stimulation [121]. However, stimulating the faucial pillars with a combination of mechanical, cold, and sour stimuli significantly decreased the latency to induce one swallow [121]. Both cold stimulation to the human anterior tonsillar pillars or application of topical anesthesia in normal subjects did not alter the regional transit time and clearance time of a bolus suggesting that stimulation of the anterior tonsillar pillars is not critical to evoking the pharyngeal swallow [102].

\section{Chemical Stimuli}

Saliva is an important sensory stimulus in the normal swallow: methods to enhance its secretion improve pharyngeal swallow elicitation. Manson and Sandberg [32, 33] counted the number of pharyngeal swallows performed in a 10 -s period when subjects sucked on different lozenges. Their data showed that while the task was difficult without lozenges, neutral lozenges facilitated saliva secretion, and the best performance was seen with sour lozenges.

There are water-specific receptors in the pharyngeal region (particularly in the supraglottic space) that are vital to evoking a pharyngeal phase swallow [84, 85, 94]. Injection of water $(0.3$ and $0.6 \mathrm{ml})$ into the pharynx in healthy human subjects induces pharyngeal swallowing and closure of the larynx (i.e., pharyngoglottal closure reflex) $[122,123]$. Adding potassium chloride to water in different concentrations differentially excites receptors that elicit pharyngeal swallowing [25, 26].

Taste pathways may also be used to lower the threshold to evoke swallowing [124]. Taste sensory input synapses almost exclusively in the NTS, but predominantly in regions rostral to the subnuclei that contain interneurons vital to eliciting swallowing [63]. Many of the sensory fibers that terminate in the NTS respond to potassium chloride and hydrogen chloride [25, 26, 41]. Acetic acid and citric acid evoke swallowing more effectively than other solutions in anesthetized rats. Acetic acid evokes swallowing in regions innervated by the GPN pharyngeal branch and the iSLN. Water is effective in the iSLN region but only slightly in the GPNph region.

Logemann et al. [125] measured differences between swallowing a regular barium suspension and a sour barium suspension prepared in a $50 \%$ ratio with lemon juice in patients with neurogenic dysphagia. Both oral and pharyngeal transit times were shortened with the sour bolus. Further research by Hamdy et al. [126] used a fairly lowintensity solution of $10 \%$ citric acid and showed little or no change to swallowing. This raises the possibility that the effect observed by Logemann and Lawless [127] relied on a high intensity of citric acid, sufficient to suggest to some investigators that the stimulus is activating trigeminal nociceptive pathways. Improved swallow onset timing with sour stimuli may be facilitated by such nociceptive mechanisms and will require further study [125, 127, 128].

Despite these studies that evaluate sensory input affecting swallowing, research in normal subjects has also suggested that locally anesthetizing the oral and pharyngeal mucosa did not affect the regional transit and clearance times as assessed by videoradiography and manometry [129]. However, local anesthetizing the pharyngeal mucosa did significantly reduce the duration of the midpharyngeal contraction wave but not its amplitude.

\section{Esophageal Responses to Different Stimuli}

Different esophageal reflexes can be induced depending on the site and type of sensory stimulation [130]. Reflexes can be elicited based on the inflation rate of air distension to the esophagus. Primary peristalsis is induced by stimulation in the pharynx and the initiation of pharyngeal swallowing, while secondary peristalsis is induced by direct stimulation in the esophagus [28-30]. Inhibition of both primary and secondary peristalsis occurs with rapid water injection into the pharynx evoking repeated pharyngeal swallows [131, 132] and with air injection into the esophagus [133]. Rapid air injection into the pharynx induces UES contraction and lower esophageal sphincter (LES) relaxation and inhibits esophageal peristalsis $[134,135]$. When air is injected into the esophagus above the level of a distending balloon, the 
UES relaxes [136]. Air injection below the balloon induces increased UES contraction. Both contractile and inhibitory LES reflexes can be induced via sensory input from the pharynx, larynx, stomach, and esophagus [137]. Infusion of lidocaine into the human esophagus decreases the number of times air distension can induce secondary peristalsis [138].

Studies in the anesthetized cat have evaluated whether vagal sensory fibers innervating the esophagus can be sensitized by acid infusion to mimic problems with acid reflux in the human [139]. These vagal sensory fibers respond normally to graded esophageal distension, increasing their discharge with more distension. Infusion of acid with pepsin into the esophagus does not change the response to distension. However, neurons in the brainstem do become modified, suggesting that acid in the esophagus may alter sensory input and its affect centrally [139].

\section{Sensory Input and the Cortex}

Increased sensory input can modify motor areas of the cerebral cortex, fostering the concept that increased sensory input might be useful in rehabilitating dysphagic patients with cortical strokes [140, 141]. Some sensory inputs may induce cortical reflexes [142, 143]. Stimulation of the iSLN induces a reflex in the recurrent laryngeal nerve, activity in interneurons in the NTS, and simultaneous rostral activation of multiple cortical sites, including a cortical descending reflex that can affect the motoneurons in the cranial motor nuclei and interneurons in the NTS swallowing pathway [144]. If pharyngeal stimulation with a single electrical pulse is given prior to transcranial magnetic stimulation (TMS) to the motor cortex, the TMS facilitates the pharyngeal evoked potential elicited from the cortex [142]. Pharyngeal stimulation induces increased excitability of the swallowing cortex and short-term improvements in swallowing in dysphagic stroke patients. Stimulation of the pharynx can change the motor cortex and increases the area of representation of the pharynx, but it simultaneously decreases the esophageal representation [143]. For at least $30 \mathrm{~min}$ after pharyngeal stimulation, motor cortex excitability and the area of pharyngeal representation increased, suggesting potential ideas of protocols to enhance swallowing motor expression [145].

\section{Future Directions}

This review has summarized the current state of knowledge regarding the anatomy that subserves sensory input to swallow initiation and modulation and evidence supporting the potential for modulation of swallowing in response to sensory stimuli. Synthesis of this information reveals a number of areas for possible future research. These can be grouped under the themes of (1) effective mechanisms and stimuli for sensory modulation, (2) pressure and tactile stimuli, and (3) chemical stimuli.

\section{Effective Mechanisms and Stimuli for Sensory Modulation}

An early animal study by Doty [5] using iSLN stimulation found that optimum frequencies to evoke swallowing were between 30 and $50 \mathrm{~Hz}$ in the anesthetized dog, monkey, and cat. Outside these frequencies, swallows were evoked only with higher-intensity current. The optimum frequency of electrical stimulation to a peripheral nerve means that a pattern of excitation must be applied to sensory fibers of different diameters [146] and that this pattern must be detected in the dorsal NTS swallowing group in order to trigger specific interneurons to start the swallow [54, 91, 147]. However, electrical stimulation of a peripheral nerve is a nonphysiological form of stimulation that excites the largest-diameter fibers [146] first, rendering it an artificial approach to stimulation. Future studies of sensory modulation of swallowing in the human with a damaged or impaired CNS may rely on techniques that use electrical sensory patterns similar to those studies ongoing in the auditory system with cochlear implants or with stimulation of peripheral nerve [148, 149].

\section{Pressure and Tactile Stimuli}

Larger boluses elicit shorter latencies to pharyngeal swallow onset and increased muscle contractile activity [101, 104]. Such findings suggest that a larger bolus moving across more receptive fields excites more sensory fibers which synapse in the NTS and enhance the NTS drive of the motoneurons. This hypothesis has yet to be confirmed experimentally.

\section{Chemical Stimuli}

Few studies have controlled for or explored the olfactory aspects of stimuli that might affect swallowing [35]. Olfactory inputs appear to enhance pharyngeal swallowing through increasing salivation. Bülow et al. [150] have studied carbonation as a stimulus to evoke swallowing, but it remains unclear which characteristics of carbonated stimuli might be important in evoking swallowing. Gas in a swallowed bolus may constitute both a touch-pressure stimulus and a dynamic taste or chemesthetic stimulus.

\section{Summary}

Boluses of liquids and solids normally initiate pharyngeal swallowing using multiple modalities, including taste, 
water, touch, pressure, and possibly temperature to excite several types of sensory fibers of different diameters that innervate the receptors in the oropharyngeal mucosa. It appears that stimulation of a greater number of receptive fields and their individual sensory neurons induces a stronger reflex with greater muscle recruitment and force. Movement of portions of a bolus to the hypopharyngeal region will induce the pharyngeal swallowing reflex with a shorter latency. Stimulation of the oral region, which includes the pillars of fauci, appears to facilitate swallow reflex initiation, with air puffs and combined thermal-gustatory-tactile stimuli eliciting preferential responses. Enhancement of salivation, including the use of visual and olfactory stimuli, also appears to facilitate the evoking of swallowing. The potential of enhancing stimuli to the mucosa through air puffs appears promising and follows some of the excellent studies using sour boluses and sour stimuli with other stimuli. Many of these findings are drawn from experiments in animals or observations of swallowing in healthy humans. Therefore, these conclusions lay the foundation for future experiments in which specific sensory inputs may be further examined for their potential to elicit and modulate swallowing in humans with dysphagia.

Acknowledgments This review article was born out of conversations at a meeting in Christchurch, New Zealand, in 2005. We recognize Dr. Maggie-Lee Huckabee, who had the vision to organize that meeting and initiate those discussions. The first author acknowledges the support of the Toronto Rehabilitation Institute which receives funding under the Provincial Rehabilitation Research Program from the Ministry of Health and Long-term Care in Ontario. The views expressed do not necessarily reflect those of the ministry.

Open Access This article is distributed under the terms of the Creative Commons Attribution Noncommercial License which permits any noncommercial use, distribution, and reproduction in any medium, provided the original author(s) and source are credited.

\section{References}

1. Martin RE. Neuroplasticity and swallowing. Dysphagia. 2009;24: 218-29.

2. Martin-Harris B, Brodsky MB, Michel Y, Castell DO, Schleicher M, Sandidge J, Maxwell R, Blair J. MBS measurement tool for swallow impairment-MBSImp: establishing a standard. Dysphagia. 2008;23:392-405.

3. Takahashi T, Miyamoto T, Terao A, Yokoyama A. Cerebral activation related to the control of mastication during changes in food hardness. Neuroscience. 2007;145:791-4.

4. Minato A, Ono T, Miyamoto JJ, Honda E, Kurabayashi T, Moriyama K. Preferred chewing side-dependent two-point discrimination and cortical activation pattern of tactile tongue sensation. Behav Brain Res. 2009;203:118-26.

5. Doty R. Influence of stimulus pattern on reflex deglutition. Am J Physiol. 1951;166:142-55.

6. Doty R, Bosma JF. An electromyographic analysis of reflex deglutition. J Neurophysiol. 1956;19:44-60.
7. Dong H, Loomis CW, Bieger D. Vagal afferent input determines the volume dependence of rat esophageal motility patterns. Am J Physiol Gastrointest Liver Physiol. 2001;281:G44-53.

8. Lowell SY, Poletto CJ, Knorr-Chung BR, Reynolds RC, Simonyan K, Ludlow CL. Sensory stimulation activates both motor and sensory components of the swallowing system. Neuroimage. 2008;42:285-95.

9. Martin RE, Goodyear BG, Gati JS, Menon RS. Cerebral cortical representation of automatic and volitional swallowing in humans. J Neurophysiol. 2001;85:938-50.

10. Martin RE, MacIntosh BJ, Smith RC, Barr AM, Stevens TK, Gati JS, Menon RS. Cerebral areas processing swallowing and tongue movement are overlapping but distinct: a functional magnetic resonance imaging study. J Neurophysiol. 2004;92: 2428-43.

11. Martin RE, Sessle BJ. The role of the cerebral cortex in swallowing. Dysphagia. 1993;8:195-202.

12. Hamdy S, Rothwell JC, Aziz Q, Thompson DG. Organization and reorganization of human swallowing motor cortex: implications for recovery after stroke. Clin Sci (Lond). 2000;99: $151-7$.

13. Hamdy S, Aziz Q, Thompson DG, Rothwell JC. Physiology and pathophysiology of the swallowing area of human motor cortex. Neural Plast. 2001;8:91-7.

14. Hamdy S, Rothwell JC, Brooks DJ, Bailey D, Aziz Q, Thompson DG. Identification of the cerebral loci processing human swallowing with H2(15)O PET activation. J Neurophysiol. 1999;81:1917-26.

15. Hamdy S, Mikulis DJ, Crawley A, Xue S, Lau H, Henry S, Diamant NE. Cortical activation during human volitional swallowing: an event-related fMRI study. Am J Physiol. 1999; 277:G219-25.

16. Hamdy S, Aziz Q, Rothwell JC, Crone R, Hughes D, Tallis RC, Thompson DG. Explaining oropharyngeal dysphagia after unilateral hemispheric stroke. Lancet. 1997;350:686-92.

17. Daniels SK, Corey DM, Barnes CL, Faucheaux NM, Priestly $\mathrm{DH}$, Foundas AL. Cortical representation of swallowing: a modified dual task paradigm. Percept Mot Skills. 2002;94: 1029-40.

18. Doty R, Richmond WH, Storey A. Effect of medullary lesions on coordination of deglutition. Exp Neurol. 1968;17:91-106.

19. Hrycyshyn AW, Basmajian JV. Electromyography of the oral stage of swallowing in man. Am J Anat. 1972;133:333-40.

20. Kitagawa J, Shingai T, Takahashi Y, Yamada Y. Pharyngeal branch of the glossopharyngeal nerve plays a major role in reflex swallowing from the pharynx. Am J Physiol Regul Integr Comp Physiol. 2002;282:R1342-7.

21. Pommerenke W. A study of the sensory areas eliciting the swallowing reflex. Am J Physiol. 1928;84:36-41.

22. Sweazey R, Bradley R. Responses of neurons in the lamb nucleus tractus solitarius to stimulation of the caudal oral cavity and epiglottis with different stimulus modalities. Brain Res. 1989;480:133-50.

23. Sweazey RD, Bradley RM. Response characteristics of lamb pontine neurons to stimulation of the oral cavity and epiglottis with different sensory modalities. J Neurophysiol. 1993;70: 1168-80.

24. Thexton AJ. Oral reflexes elicited by mechanical stimulation of palatal mucosa in the cat. Arch Oral Biol. 1973;18(8):977-80.

25. Shingai J. Ionic mechanisms of water receptors in the laryngeal mucosa of the rabbit. Jpn J Physiol. 1977;27:27-42.

26. Shingai T, Shimada K. Reflex swallowing elicited by water and chemical substances. Jpn J Physiol. 1976;26:455-69.

27. Sengupta JN. Electrophysiological recording from neurons controlling sensory and motor functions of the esophagus. Am J Med. 2001;111(Suppl 8A):169S-73S. 
28. Janssens J, De Wever I, Vantrappen G, Hellemans J. Peristalsis in smooth muscle esophagus after transection and bolus deviation. Gastroenterology. 1976;71:1004-9.

29. Janssens J, Valembois P, Hellemans J, Vantrappen G, Pelemans W. Studies on the necessity of a bolus for the progression of secondary peristalsis in the canine esophagus. Gastroenterology. 1974;67:245-51.

30. Janssens J, Valembois P, Vantrappen G, Hellemans J, Pelemans $\mathrm{W}$. Is the primary peristaltic contraction of the canine esophagus bolus-dependent? Gastroenterology. 1973;65:750-6.

31. Janssens J, Vantrappen G, Hellemans J. Neural control of primary esophageal peristalsis. Gastroenterology. 1978;74:801-3.

32. Mansson I, Sandberg N. Effects of surface anesthesia on deglutition in man. Laryngoscope. 1974;84:427-37.

33. Mansson I, Sandberg N. Salivary stimulus and swallowing in man. Acta Otolaryngol. 1975;79:445-50.

34. Rudney JD, Ji Z, Larson CJ. The prediction of saliva swallowing frequency in humans from estimates of salivary flow rate and the volume of saliva swallowed. Arch Oral Biol. 1995;40:507-12.

35. Ebihara T, Ebihara S, Maruyama M, Kobayashi M, Itou A, Arai $\mathrm{H}$, Sasaki H. A randomized trial of olfactory stimulation using black pepper oil in older people with swallowing dysfunction. J Am Geriatr Soc. 2006;54:1401-6.

36. Maeda K, Ono T, Otsuka R, Ishiwata Y, Kuroda T, Ohyama K. Modulation of voluntary swallowing by visual inputs in humans. Dysphagia. 2004;19:1-6.

37. Sweazey R, Bradley R. Response characteristics of lamb trigeminal neurons to stimulation of the oral cavity and epiglottis with different sensory modalities. Brain Res Bull. 1989;22: 883-91.

38. Kawagishi S, Kou F, Yoshino K, Tanaka T, Masumi S. Decrease in stereognostic ability of the tongue with age. J Oral Rehabil. 2009;36:872-9.

39. Pouderoux P, Kahrilas PJ. Deglutitive tongue force modulation by volition, volume, and viscosity in humans. Gastroenterology. 1995;108:1418-26.

40. Ali GN, Cook IJ, Laundl TM, Wallace KL, de Carle DJ. Influence of altered tongue contour and position on deglutitive pharyngeal and UES function. Am J Physiol. 1997;273:G1071-6.

41. Bradley RM, Sweazey RD. In vitro intracellular recordings from gustatory neurons in the rat solitary nucleus. Brain Res. 1990;508:160-71.

42. Bradley RM, Sweazey RD. Separation of neuron types in the gustatory zone of the nucleus tractus solitarii on the basis of intrinsic firing discharges. J Neurophyiol. 1992;67:1659-68.

43. Hockman CH, Bieger D, Weerasuriya A. Supranuclear pathways of swallowing. Prog Neurobiol. 1979;12:15-32.

44. Mu L, Sanders I. Sensory nerve supply of the human oro- and laryngopharynx: a preliminary study. Anat Rec. 2000;258: 406-20.

45. Bradley RM, Mistretta CM. Swallowing in fetal sheep. Science. 1973;179:1016-7.

46. Bradley RM, Mistretta CM. Fetal sensory receptors. Physiol Rev. 1975;55:352-82.

47. Bradley R. Development of the taste bud and gustatory papillae in human fetuses. In: Bosma JF, editor. Oral sensation and perception. Springfield, IL: Charles C. Thomas; 1972. p. $137-62$.

48. Feindel W. The neural pattern of the epiglottis. J Comp Neurol. 1956;105:269-85.

49. Sampson S, Eyzaguirre C. Some functional characteristics of mechanoreceptors in the larynx of the cat. J Neurophysiol. 1964;27:464-80.

50. Ichikawa H, Jacobowitz DM, Sugimoto T. Calretinin-immunoreactivity in the oro-facial and pharyngeal regions of the rat. Neurosci Lett. 1992;146:155-8.
51. Broussard DL, Altschuler SM. Central integration of swallow and airway-protective reflexes. Am J Med. 2000;108(Suppl 4a): 62S-7S.

52. Broussard DL, Altschuler SM. Brainstem viscerotopic organization of afferents and efferents involved in the control of swallowing. Am J Med. 2000;108(Suppl 4a):79S-86S.

53. Jean A, Amri M, Calas A. Connections between the ventral medullary swallowing area and the trigeminal motor nucleus of the sheep studied by tracing techniques. J Auton Nerv Syst. 1983;7:87-96.

54. Jean A, Car A. Inputs to the swallowing medullary neurons from the peripheral afferent fibers and the swallowing cortical area. Brain Res. 1979; 178:567-72.

55. Sumi T. Reticular ascending activation of frontal cortical neurons in rabbits, with special reference to the regulation of deglutition. Brain Res. 1972;46:43-54.

56. Sumi T. Role of the pontine reticular formation in the neural organization of deglutition. Jpn J Physiol. 1972;22:295-314.

57. Sumi T. Neuronal mechanisms in swallowing. Pflugers Arch Gesamte Physiol Menschen Tiere. 1964;278:467-77.

58. Amri M, Car A, Jean A. Medullary control of the pontine swallowing neurones in sheep. Exp Brain Res. 1984;55:105-10.

59. Amri M, Car A, Roman C. Axonal branching of medullary swallowing neurons projecting on the trigeminal and hypoglossal motor nuclei: demonstration by electrophysiological and fluorescent double labeling techniques. Exp Brain Res. 1990;81:384-90.

60. Sweazey R, Bradley R. Central connections of the lingual-tonsillar branch of the glossopharyngeal nerve and the superior laryngeal nerve in lamb. J Comp Neurol. 1986;245:471-82.

61. Sweazey R, Bradley R. Response of lamb nucleus of the solitary tract neurons to chemical stimulation of the epiglottis. Brain Res. 1988;439:195-210.

62. Sweazey RD. Distribution of aspartate and glutamate in the nucleus of the solitary tract of the lamb. Exp Brain Res. 1995; 105:241-53.

63. Travers JB, Smith DV. Gustatory sensitivities in neurons of the hamster nucleus tractus solitarius. Sens Process. 1979;3:1-26.

64. Sweazey RD, Smith DV. Convergence onto hamster medullary taste neurons. Brain Res. 1987;408:173-84.

65. Travers SP, Norgren R. Organization of orosensory responses in the nucleus of the solitary tract of rat. J Neurophysiol. 1995;73: 2144-62.

66. Sengupta JN, Kauvar D, Goyal RK. Characteristics of vagal esophageal tension-sensitive afferent fibers in the opossum. J Neurophysiol. 1989;61:1001-10.

67. Sengupta JN, Saha JK, Goyal RK. Stimulus-response function studies of esophageal mechanosensitive nociceptors in sympathetic afferents of opossum. J Neurophysiol. 1990;64:796-812.

68. Sengupta JN, Saha JK, Goyal RK. Differential sensitivity to bradykinin of esophageal distension-sensitive mechanoreceptors in vagal and sympathetic afferents of the opossum. J Neurophysiol. 1992;68:1053-67.

69. Raut VV, McKee GJ, Johnston BT. Effect of bolus consistency on swallowing-does altering consistency help? Eur Arch Otorhinolaryngol. 2001;258:49-53.

70. Palmer JB, Hiiemae KM, Matsuo K, Haishima H. Volitional control of food transport and bolus formation during feeding. Physiol Behav. 2007;91:66-70.

71. Palmer JB, Rudin NJ, Lara G, Crompton AW. Coordination of mastication and swallowing. Dysphagia. 1992;7:187-200.

72. Steele CM, Van Lieshout P. Tongue movements during water swallowing in healthy young and older adults. J Speech Lang Hear Res. 2009;52:1255-67.

73. Daniels SK, Foundas AL. Swallowing physiology of sequential straw drinking. Dysphagia. 2001;16:176-82. 
74. Daniels SK, Corey DM, Hadskey LD, Legendre C, Priestly DH, Rosenbek JC, Foundas AL. Mechanism of sequential swallowing during straw drinking in healthy young and older adults. J Speech Lang Hear Res. 2004;47:33-45.

75. Martin-Harris B, Brodsky MB, Michel Y, Lee FS, Walters B. Delayed initiation of the pharyngeal swallow: normal variability in adult swallows. J Speech Lang Hear Res. 2007;50(3):585-94.

76. Daniels SK, Schroeder MF, Degeorge PC, Corey DM, Rosenbek JC. Effects of verbal cue on bolus flow during swallowing. Am J Speech Lang Pathol. 2007;16:140-7.

77. Pouderoux P, Logemann JA, Kahrilas PJ. Pharyngeal swallowing elicited by fluid infusion: role of volition and vallecular containment. Am J Physiol. 1996;270:G347-54.

78. Sant'Ambrogio G, Anderson JW, Sant'Ambrogio FB, Mathew OP. Response of laryngeal receptors to water solutions of different osmolality and ionic composition. Respir Med. 1991; 85(Suppl A):57-60.

79. Sant'Ambrogio G, Mathew OP. Laryngeal receptors and their reflex responses. Clin Chest Med. 1986;7:211-22.

80. Sant'Ambrogio G, Mathew OP, Sant'Ambrogio FB. Characteristics of laryngeal cold receptors. Respir Physiol. 1988;71: 287-97.

81. Sant'Ambrogio FB, Anderson JW, Kuna ST, Sant'Ambrogio G. Effect of changes in airway surface liquid on laryngeal receptors and muscles. Respir Physiol. 1995;101:31-9.

82. Sinclair W. Initiation of reflex swallowing from the naso- and oropharnyx. Am J Physiol. 1970;221:956-90.

83. Sinclair W. Role of the pharyngeal plexus in initiation of swallowing. Am J Physiol. 1971;221:1260-3.

84. Storey A. A functional analysis of sensory units innervating epiglottis and larynx. Exp Neurol. 1968;20:366-83.

85. Storey A. Laryngeal initiation of swallowing. Exp Neurol. 1968;20:359-65.

86. Jafari S, Prince RA, Kim DY, Paydarfar D. Sensory regulation of swallowing and airway protection: a role for the internal superior laryngeal nerve in humans. J Physiol. 2003;550: 287-304.

87. Barkmeier JM, Bielamowicz S, Takeda N, Ludlow CL. Modulation of laryngeal responses to superior laryngeal nerve stimulation by volitional swallowing in awake humans. J Neurophysiol. 2000; 83:1264-72.

88. Sulica L, Hembree A, Blitzer A. Swallowing and sensation: evaluation of deglutition in the anesthetized larynx. Ann Otol Rhinol Laryngol. 2002;111:291-4.

89. Kijima H, Shingai T, Takahashi Y, Kajii Y, Fukushima S, Taguchi Y, Noda T, Yamada Y. Nitric oxide modulates elicitation of reflex swallowing from the pharynx in rats. Am J Physiol Regul Integr Comp Physiol. 2006;291:R651-6.

90. Capra N. Mechanisms of oral sensation. Dysphagia. 1995;10: 235-47.

91. Miller A. Characteristics of the swallowing reflex induced by peripheral nerve and brain stem stimulation. Exp Neurol. 1972;34:210-22.

92. Miller F, Sherrington C. Some observations on the buccopharyngeal stage of reflex deglutition in the cat. Q J Exp Physiol. 1916;9:147-86.

93. Sumi T. Some properties of cortically-evoked swallowing and chewing in rabbits. Brain Res. 1969;15:107-20.

94. Storey A, Johnson P. Laryngeal water receptors initiating apnea in the lamb. Exp Neurol. 1975;47:42-55.

95. Yahagi R, Okuda-Akabane K, Fukami H, Matsumoto N, Kitada Y. Facilitation of voluntary swallowing by chemical stimulation of the posterior tongue and pharyngeal region in humans. Neurosci Lett. 2008;448:139-42.

96. Dua K, Bardan E, Ren J, Sui Z, Shaker R. Effect of chronic and acute cigarette smoking on the pharyngo-upper oesophageal sphincter contractile reflex and reflexive pharyngeal swallow. Gut. 1998;43:537-41.

97. Dua K, Bardan E, Ren J, Sui Z, Shaker R. Effect of chronic and acute cigarette smoking on the pharyngoglottal closure reflex. Gut. 2002;51:771-5.

98. Lazarus CL, Logemann JA, Rademaker AW, Kahrilas PJ, Pajak T, Lazar R, Halper A. Effects of bolus volume, viscosity, and repeated swallows in nonstroke subjects and stroke patients. Arch Phys Med Rehabil. 1993;74:1066-70.

99. Kahrilas PJ, Lin S, Logemann JA, Ergun GA, Facchini F. Deglutitive tongue action: volume accommodation and bolus propulsion. Gastroenterology. 1993;104:152-62.

100. Kahrilas PJ, Logemann JA. Volume accommodation during swallowing. Dysphagia. 1993;8:259-65.

101. Dantas RO, Kern MK, Massey BT, Dodds WJ, Kahrilas PJ, Brasseur JG, Cook IJ, Lang IM. Effect of swallowed bolus variables on oral and pharyngeal phases of swallowing. Am J Physiol. 1990;258:G675-81.

102. Ali GN, Laundl TM, Wallace KL, deCarle DJ, Cook IJ. Influence of cold stimulation on the normal pharyngeal swallow response. Dysphagia. 1996;11:2-8.

103. Christensen CM, Casper LM. Oral and nonoral perception of solution viscosity. J Food Sci. 1987;52:445-7.

104. Dantas RO, Dodds WJ. Effect of bolus volume and consistency on swallow-induced submental and infrahyoid electromyographic activity. Braz J Med Biol Res. 1990;23:37-44.

105. Chi-Fishman G, Sonies BC. Effects of systematic bolus viscosity and volume changes on hyoid movement kinematics. Dysphagia. 2002;17:278-87.

106. Aviv JE. Clinical assessment of pharyngolaryngeal sensitivity. Am J Med. 2000;108(Suppl 4a):68S-72S.

107. Aviv JE, Murry T, Zschommler A, Cohen M, Gartner C. Flexible endoscopic evaluation of swallowing with sensory testing: patient characteristics and analysis of safety in 1, 340 consecutive examinations. Ann Otol Rhinol Laryngol. 2005;114: $173-6$.

108. Aviv JE, Martin JH, Keen MS, Debell M, Blitzer A. Air pulse quantification of supraglottic and pharyngeal sensation: a new technique. Ann Otol Rhinol Laryngol. 1993;102:777-80.

109. Aviv JE, Kim T, Thomson JE, Sunshine S, Kaplan S, Close LG. Fiberoptic endoscopic evaluation of swallowing with sensory testing (FEESST) in healthy controls. Dysphagia. 1998;13: $87-92$.

110. Kawamura O, Easterling C, Aslam M, Rittmann T, Hofmann C, Shaker R. Laryngo-upper esophageal sphincter contractile reflex in humans deteriorates with age. Gastroenterology. 2004;127: 57-64.

111. Kawamura O, Easterling C, Rittmann T, Hofmann C, Shaker R. Optimal stimulus intensity and reliability of air stimulation technique for elicitation of laryngo-upper esophageal sphincter contractile reflex. Ann Otol Rhinol Laryngol. 2005;114:223-8.

112. Aviv JE, Martin JH, Jones ME, Wee TA, Diamond B, Keen MS, Blitzer A. Age-related changes in pharyngeal and supraglottic sensation. Ann Otol Rhinol Laryngol. 1994;103:749-52.

113. Theurer JA, Bihari F, Barr AM, Martin RE. Oropharyngeal stimulation with air-pulse trains increases swallowing frequency in healthy adults. Dysphagia. 2005;20:254-60.

114. Theurer JA, Czachorowski KA, Martin LP, Martin RE. Effects of oropharyngeal air-pulse stimulation on swallowing in healthy older adults. Dysphagia. 2009;24:302-13.

115. Chi-Fishman G, Capra NF, McCall GN. Thermomechanical facilitation of swallowing evoked by electrical nerve stimulation in cats. Dysphagia. 1994;9:149-55.

116. Kaatzke-McDonald MN, Post E, Davis PJ. The effects of cold, touch, and chemical stimulation of the anterior faucial pillar on human swallowing. Dysphagia. 1996;11:198-206. 
117. Rosenbek JC, Robbins J, Fishback B, Levine RL. Effects of thermal application on dysphagia after stroke. J Speech Hear Res. 1991;34:1257-68.

118. Rosenbek JC, Robbins J, Willford WO, Kirk G, Schiltz A, Sowell TW, Deutsch SE, Milanti FJ, Ashford J, Gramigna GD, Fogarty A, Dong K, Rau MT, Prescott TE, Lloyd AM, Sterkel MT, Hansen JE. Comparing treatment intensities of tactilethermal application. Dysphagia. 1998;13:1-9.

119. Rosenbek JC, Roecker EB, Wood JL, Robbins J. Thermal application reduces the duration of stage transition in dysphagia after stroke. Dysphagia. 1996;11:225-33.

120. GdL Lazzara, Lazarus C, Logemann J. Impact of thermal stimulation on the triggering of swallowing reflex. Dysphagia. 1986;1:73-7.

121. Sciortino K, Liss JM, Case JL, Gerritsen KG, Katz RC. Effects of mechanical, cold, gustatory, and combined stimulation to the human anterior faucial pillars. Dysphagia. 2003;18:16-26.

122. Shaker R, Medda BK, Ren J, Jaradeh S, Xie P, Lang IM. Pharyngoglottal closure reflex: identification and characterization in a feline model. Am J Physiol. 1998;275:G521-5.

123. Shaker R, Ren J, Bardan E, Easterling C, Dua K, Xie P, Kern M. Pharyngoglottal closure reflex: characterization in healthy young, elderly and dysphagic patients with predeglutitive aspiration. Gerontology. 2003;49:12-20.

124. Kajii Y, Shingai T, Kitagawa J, Takahashi Y, Taguchi Y, Noda T, Yamada Y. Sour taste stimulation facilitates reflex swallowing from the pharynx and larynx in the rat. Physiol Behav. 2002;77:321-5.

125. Logemann JA, Pauloski BR, Colangelo L, Lazarus C, Fujiu M, Kahrilas PJ. Effects of a sour bolus on oropharyngeal swallowing measures in patients with neurogenic dysphagia. J Speech Hear Res. 1995;38:556-63.

126. Hamdy S, Jilani S, Price V, Parker C, Hall N, Power M. Modulation of human swallowing behaviour by thermal and chemical stimulation in health and after brain injury. Neurogastroenterol Motil. 2003;15:69-77.

127. Pelletier CA, Lawless HT. Effect of citric acid and citric acidsucrose mixtures on swallowing in neurogenic oropharyngeal dysphagia. Dysphagia. 2003;18:231-41.

128. Pelletier CA, Dhanaraj GE. The effect of taste and palatability on lingual swallowing pressure. Dysphagia. 2006;21:121-8.

129. Ali GN, Laundl TM, Wallace KL, Shaw DW, Decarle DJ, Cook IJ. Influence of mucosal receptors on deglutitive regulation of pharyngeal and upper esophageal sphincter function. Am J Physiol. 1994;267:G644-9.

130. Lang IM, Medda BK, Shaker R. Mechanisms of reflexes induced by esophageal distension. Am J Physiol Gastrointest Liver Physiol. 2001;281:G1246-63.

131. Bardan E, Xie P, Ren J, Dua K, Shaker R. Effect of pharyngeal water stimulation on esophageal peristalsis and bolus transport. Am J Physiol. 1997;272:G265-71.

132. Bardan E, Saeian K, Xie P, Ren J, Kern M, Dua K, Shaker R. Effect of pharyngeal stimulation on the motor function of the esophagus and its sphincters. Laryngoscope. 1999;109:437-41.

133. Bardan E, Xie P, Aslam M, Kern M, Shaker R. Disruption of primary and secondary esophageal peristalsis by afferent stimulation. Am J Physiol Gastrointest Liver Physiol. 2000;279: G255-61.

134. Pouderoux P, Shi G, Tatum RP, Kahrilas PJ. Esophageal solid bolus transit: studies using concurrent videofluoroscopy and manometry. Am J Gastroenterol. 1999;94:1457-63.
135. Pouderoux P, Verdier E, Kahrilas PJ. Patterns of esophageal inhibition during swallowing, pharyngeal stimulation, and transient LES relaxation. Lower esophageal sphincter. Am J Physiol Gastrointest Liver Physiol. 2003;284:G242-7.

136. Aslam M, Kern M, Shaker R. Modulation of oesophago-UOS contractile reflex: effect of proximal and distal esophageal distention and swallowing. Neurogastroenterol Motil. 2003;15: 323-9.

137. Gawrieh S, Shaker R. Peripheral mechanisms affecting the lower esophageal sphincter tone. Gastroenterol Clin North Am. 2002;31:S21-33.

138. Bartolome G, Neumann S. Swallowing therapy in patients with neurological disorders causing cricopharyngeal dysfunction. Dysphagia. 1993;8:146-9.

139. Medda BK, Sengupta JN, Lang IM, Shaker R. Response properties of the brainstem neurons of the cat following intra-esophageal acid-pepsin infusion. Neuroscience. 2005;135:1285-94.

140. Gow D, Hobson AR, Furlong P, Hamdy S. Characterising the central mechanisms of sensory modulation in human swallowing motor cortex. Clin Neurophysiol. 2004;115:2382-90.

141. Gow D, Rothwell J, Hobson A, Thompson D, Hamdy S. Induction of long-term plasticity in human swallowing motor cortex following repetitive cortical stimulation. Clin Neurophysiol. 2004;115:1044-51.

142. Hamdy S, Aziz Q, Rothwell JC, Hobson A, Barlow J, Thompson DG. Cranial nerve modulation of human cortical swallowing motor pathways. Am J Physiol. 1997;272:G802-8.

143. Hamdy S, Rothwell JC, Aziz Q, Singh KD, Thompson DG. Long-term reorganization of human motor cortex driven by short-term sensory stimulation. Nat Neurosci. 1998;1:64-8.

144. Teismann IK, Dziewas R, Steinstraeter O, Pantev C. Timedependent hemispheric shift of the cortical control of volitional swallowing. Hum Brain Mapp. 2009;30:92-100.

145. Fraser C, Rothwell J, Power M, Hobson A, Thompson D, Hamdy S. Differential changes in human pharyngoesophageal motor excitability induced by swallowing, pharyngeal stimulation, and anesthesia. Am J Physiol Gastrointest Liver Physiol. 2003;285:G137-44.

146. Miller AJ, Loizzi RF. Anatomical and functional differentiation of superior laryngeal nerve fibers affecting swallowing and respiration. Exp Neurol. 1974;42:369-87.

147. Jean A, Car A, Roman C. Study by means of microelectrodes of bulbar deglutitory neuron activity. J Physiol (Paris). 1970; 62(Suppl 1):170.

148. Kezirian EJ, Boudewyns A, Eisele DW, Schwartz AR, Smith PL, Van de Heyning PH, De Backer WA. Electrical stimulation of the hypoglossal nerve in the treatment of obstructive sleep apnea. Sleep Med Rev. 2010. doi:10.1016/j.smrv.2009.10.009.

149. Litvak L, Delgutte B, Eddington D. Auditory nerve fiber responses to electric stimulation: modulated and unmodulated pulse trains. J Acoust Soc Am. 2001;110:368-79.

150. Bulow M, Olsson R, Ekberg O. Videoradiographic analysis of how carbonated thin liquids and thickened liquids affect the physiology of swallowing in subjects with aspiration on thin liquids. Acta Radiol. 2003;44:366-72.

\section{Catriona M. Steele PhD}

\section{Arthur J. Miller PhD}

